\title{
A FORMAÇÃO CONTINUADA DE PROFESSORES DA EDUCAÇÃO INFANTIL
}

\author{
Camila da Silva Rondon Campos ${ }^{1}$ \\ Cleuza da Silva Freire ${ }^{2}$ \\ Dagmar Modesto Batista Barros ${ }^{3}$ \\ Irineide Santos Costa ${ }^{4}$ \\ Mickyciele da Silva Caldas Almeida ${ }^{5}$ \\ Rosidete Conceição da Silva Gaudêncio ${ }^{6}$ \\ Ruan Felipe da Silva Cesário ${ }^{7}$
}

RESUMO: O objetivo deste artigo é refletir sobre a formação continuada de educadores da primeira infância, enfocando nossos modelos fundamentais de formação em interface com a pedagogia crítica de autores como Adorno (1995), Alarcão (200I), Behrens (2007), Freire (1996), Giroux (1997), Mclaren (1997), Névoa (1995), entre outros. Este artigo expõe os teóricos da formação continuada, de forma sintética, enfatizando que a formação continuada nos conscientiza que nos leva ao humano, à verdadeira libertação em busca de emancipação ou empoderamento. Apresentamos também um panorama dos modelos de formação que influenciaram e continuam a influenciar a formação de professores em nosso país, articulando-se com a pedagogia crítica no sentido de colocar problemas conceituais, reformar práticas, levar à construção de uma consciência crítica. A reflexão aqui abordada nos leva a perceber que a pedagogia crítica deve nortear nossa formação continuada, levando-nos a reconhecer e transformar os traços antidemocráticos e opressores da hegemonia do regime para dar um novo sentido à prática docente.

Palavras-chave: Formação continuada. Paradigmas. Pedagogia crítica.

\footnotetext{
I Graduada em Pedagogia pela Universidade Federal de Mato Grosso - UFMT, Especialista em Educação Infantil pelas Faculdades Integradas de Várzea Grande - FIAVEC.

${ }^{2}$ Graduada em Pedagogia - Educação Infantil pela Universidade Federal de Mato Grosso, Especialista em Docência na Educação Infantil pela Universidade Federal de Mato Grosso - UFMT.

3 Graduada em Pedagogia pela Universidade de Cuiabá - UNIC, Especialista em Educação Especial Atendimento Educacional Especializado pela Faculdade de Educação de Tangará da Serra - UNISERRA.

${ }^{4}$ Graduada em Pedagogia pela Faculdade UNIVEST de Educação, Especialista em Educação Infantil e Letramento pela Faculdade UNIVEST de Educação.

${ }_{5}^{5}$ Graduada em Pedagogia pela Universidade Pitágoras - UNOPAR, Especialista em Educação Infantil: prática pedagógica pela Faculdade - FAVENI.

${ }^{6}$ Graduada em Pedagogia pelo Centro Universitário Cândido Rondon - UNIRONDON, Especialista em Docência na Educação Infantil pela Universidade Federal de Mato Grosso - UFMT, Especialista em Relações Raciais no Contexto do EJA - Educação de Jovens e Adultos pela Universidade Federal de Mato Grosso UFMT, Especialista em Informática na Educação.

7 Graduado em Pedagogia pela Faculdade INVEST de Ciências e Tecnologia, Especialista em Atendimento Educaional Especializado - AEE pela Faculdade INVEST de Ciências e Tecnologia.
} 
ABSTRACT: The aim of this article is to reflect on the continuing education of early childhood educators, focusing on our fundamental training models in interface with the critical pedagogy of authors such as Adorno (1995), Alarcão (2001), Behrens (2007), Freire ( 1996), Giroux (1997), Mclaren (1997), Mist (1995), among others. This article exposes continuing education theorists, in a synthetic way, emphasizing that continuing education makes us aware that leads us to the human, to true liberation in search of emancipation or empowerment. We also present an overview of the training models that have influenced and continue to influence teacher education in our country, linking with critical pedagogy in the sense of posing conceptual problems, reforming practices, leading to the construction of a critical conscience. The reflection addressed here leads us to realize that critical pedagogy must guide our continuing education, leading us to recognize and transform the anti-democratic and oppressive traits of the regime's hegemony in order to give a new meaning to teaching practice.

keywords: Continuing education. Paradigms. Critical pedagogy.

\section{INTRODUÇÃO}

No contexto atual, a formação continuada de professores tem sido tema recorrente nas discussões, reflexões e aprofundamento dos educadores que compreendem a importância do fenômeno educativo. Nesse sentido a formação continuada de professores da educação infantil se insere como campo investigativo amplo, tendo em vista ser uma realidade que apresenta especificidades que exigem do professor sólida formação teórico-prática e atualização permanente a partir de um compromisso ético político com a melhoria deste nível de ensino.

Assim, o desenvolvimento deste artigo objetiva refletir acerca da formação continuada de professores da educação infantil tendo como foco os paradigmas subjacentes à nossa formação na interface com a pedagogia crítica que se traduz nas exigências do mundo atual acerca de práticas docentes questionadoras e problematizadoras vivenciadas a partir de teóricos da pedagogia crítica.

\section{DESENVOLVIMENTO}

2.I Formação Continuada de Professores

O paradigma conservador com sua visão de ensino tradicional, com atitude passiva dos alunos, permanece na prática docente de muitos professores no século XXI e acreditamos ser necessário uma tomada de posição a fim de que possamos atuar de forma 
crítica e reflexiva e consigamos reconstruir nossa identidade pessoal e profissional permanentemente.

A ação opressora das formações continuadas de professores da educação infantil que tratam os professores como objeto de manipulação política, como seres que não pensam por si é necessário confrontar e buscar a nossa liberdade pessoal e profissional. É triste vermos, formações docentes baseadas apenas na técnica, no saber fazer docente impedindo a competência profissional a partir da reflexividade, do aprofundamento teórico, da mobilização dos saberes, da organização de sua própria prática, mediante seu contexto de atuação. Vemos a cada dia professores com acúmulo de atividades e responsabilidades por resultados, por premiações, "esquecendo-se" de buscar sua qualificação docente, permanecendo acomodados, adaptados, imersos à engrenagem de uma escola e de uma estrutura dominadora.

É necessário revelar a situação de opressão, controle e desumanização que vivemos no momento atual nas escolas públicas e buscarmos como dizia Freire (2013) a nossa vocação ontológica e histórica de ser mais. Para tanto é necessário, além dos conhecimentos teóricos e legais que fundamentam a formação dos professores deste nível de ensino, a ação dialógica e reflexiva das condições concretas de nossa prática docente, para uma atuação autêntica, libertadora. É um desafio à prática docente, pois percebemos a necessidade de superar paradigmas de formação que foram interiorizados durante toda a vida, romper normas estabelecidas, modelos propostos que podem não ser adequados para os dias atuais, sabemos que a formação do professor não ocorre apenas na graduação, mas durante o processo educativo vivenciado no nosso dia a dia. Ao permanecer no paradigma conservador, temos que reconhecer que somos opressores, que veem os professores:

[...] como oprimidos, acomodados e adaptados imersos na sua própria engrenagem da estrutura dominadora, temem a liberdade, enquanto não se sentem capazes de correr o risco de assumi-la. E a temem, na medida em que lutar por ela significa uma ameaça, não só aos que a usam para oprimir, como seus proprietários exclusivos, mas aos companheiros oprimidos, que se assustam com maiores repressões (FREIRE, 2013, p. 47).

O autor ressalta a importância do reconhecimento de nossa situação de oprimidos para a assunção, a mudança e a tomada de decisão, buscarmos a revolução, a transgressão, pois a conscientização nos remete à opção, decisão, abertura, compromisso. A nossa ação docente reflete a prática pedagógica que recebemos de nossos professores na escola, da 
educação recebida da família e das diversas interrelações durante a nossa vida. Isso significa que fomos formados, em nossa grande maioria, no paradigma conservador do século $\mathrm{XX}$ para atuar no paradigma inovador, século XXI, para tanto e a partir de uma reflexão rigorosa acerca dos pontos positivos e negativos desta formação, precisamos modificar as percepções já consolidadas, mas que, diante da realidade atual, não alcançam bons resultados para reelaborar a nossa prática docente de forma crítica.

A formação continuada de professores da educação infantil, deve acompanhar as transformações pelas quais passou este nível de ensino que está diretamente relacionada aos objetivos gerais da educação infantil citados no Referencial Curricular Nacional para a Educação Infantil (RCNEI) no sentido de levar a criança a: desenvolver uma imagem positiva de si; descobrir e conhecer progressivamente seu próprio corpo; estabelecer vínculos afetivos e de troca com adultos e crianças; estabelecer e ampliar cada vez mais as relações sociais; observar e explorar o ambiente com atitude de curiosidade em relação ao ambiente que a cerca; brincar, expressando emoções, sentimentos, pensamentos, desejos e necessidades; utilizar as diferentes linguagens ajustadas as diferentes intenções e situações; e, conhecer algumas manifestações culturais, demonstrando atitudes de interesse (BRASIL, 1998, p. 63). Portanto a formação do coletivo de professores da educação infantil deve fazer parte da rotina institucional cotidiana, possibilitando o encontro entre pares para troca de ideias sobre a prática, além de discussão e aprofundamento teórico. Neste sentido é necessário delinear de forma sucinta os paradigmas de formação que influenciaram e influenciam até hoje a formação dos professores em nosso país, na perspectiva de Alarcão (200I) e Behrens (2007) que a partir de nossa compreensão, se traduz na existência de diferentes paradigmas de formação e investigação, que se relacionam.

\subsection{Paradigmas de formação}

Os paradigmas de formação na perspectiva de Alarcão (200I) se apresentam como, paradigma tradicional, pós-moderno e emergente. $\mathrm{O}$ paradigma tradicional caracteriza-se pela transmissão do conhecimento, tendo a figura do professor uma posição superior ao aluno e centro do processo, reforça a contradição entre professor e aluno, cuja função é a transmissão do conhecimento e o aluno, recebe e acumula as informações transmitidas pelo professor. No que diz respeito ao paradigma pós-moderno, este caracteriza-se pela 
construção do conhecimento, professor e alunos são considerados construtores do conhecimento e têm a reflexão como importante aliada no processo de aprendizagem para desenvolver a visão crítica do aluno. Neste paradigma o conhecimento é construído na interação do sujeito com a realidade que o cerca e o processo ensino e aprendizagem constitui-se na investigação, reflexão e crítica. O paradigma emergente refere-se à construção de uma nova ordem na sociedade, construindo o conhecimento na interdisciplinaridade, quando há a reconstrução das diversas áreas do saber a fim de oferecer ao aluno a visão do todo. A aprendizagem ocorre na interação e ação com o mundo e com os outros. O professor é o responsável por mobilizar conhecimentos, capacidades e intensificar os questionamentos na perspectiva de desenvolver uma prática pedagógica reflexiva.

Diante da caracterização dos paradigmas de formação citados, evidencia-se que o paradigma assumido pelo professor é que norteará a sua ação pedagógica, portanto vejamos a concepção de paradigmas de formação a partir de Behrens (2007) que se traduz

nas abordagens conservadora e inovadora, permitem apresentar as diferentes denominações para as ações que envolvem a qualificação de professores.

O paradigma conservador, que envolve o treinamento e a capacitação acompanhou os professores por muitos séculos e carregou como maior herança o distanciamento entre teoria e prática e a reprodução do conhecimento. O preparo para atuar como professor esteve focalizado no domínio do conteúdo, designando-se como treinamento e capacitação. No período da Ditadura Militar existiu acentuação da concepção do tempo de qualificação, tendo o professor a função de modelar ou de conformar. Este paradigma torna legítimo a reprodução, a memorização, a fragmentação do conhecimento e a autora orienta que, na atualidade, este paradigma deve ser rompido, pois a formação não se faz por acumulação de conhecimentos, cursos e sim, "por um trabalho de reflexividade crítica sobre as práticas e de (re)construção permanente de uma identidade pessoal” (BERHENS, 2007, p. 444). A reflexividade deve assumir um papel preponderante na formação do professor, por ser um momento que o professor realiza a reflexão na ação e sobre a ação, consolidando, segundo Nóvoa (1995) seu terreno profissional de autoformação participada.

O paradigma inovador, também denominado, emergente ou da complexidade, assemelhando-se ao emergente de Alarcão (200I) propõe uma visão crítica, reflexiva e 
transformadora da educação e exige a interconexão de múltiplas abordagens, visões e abrangências (BEHRENS, 2007). Compreendemos este paradigma como mais apropriado à formação do professor de educação infantil visto que, este professor deve ter competência polivalente ou múltipla no tocante ao educar e ao cuidar, segundo RCNEI, o professor deve ter uma formação ampla visto possuir como grande objetivo a educação infantil "compreender, conhecer e reconhecer o jeito particular das crianças serem e estarem no mundo" (BRASIL, 1998, p. 22). Isto significa que a formação deve ser contínua, progressiva e ampla a fim de propiciar o desenvolvimento e o aprimoramento da teoria em aliança com a prática docente.

Assim, dizemos que a formação não se conclui, ela é permanente e os professores vão construindo e mobilizando seus saberes no metier docente, pois o núcleo central da formação é o exercício do magistério e neste exercício os professores são sujeitos sociais responsáveis pela mediação da cultura e dos saberes escolares, que em consequência se deve organizar a formação continuada. Significa dizer que a formação continuada deve corresponder às situações vivenciadas pelos professores, de acordo com os paradigmas a que se vincula, que está apoiada.

$\mathrm{Na}$ atualidade, temos à exigência de um profissional cada vez mais qualificado, que participa de uma prática constante e contínua de estudo, reflexão, discussão e experimentação coletiva. Este tipo de formação requer um conjunto diversificado de conhecimento, cabedal de saberes, a fim de exercer bem o seu quefazer docente. A formação continuada no paradigma inovador exige que o professor busque qualificação ao longo de toda a sua vida profissional, na própria escola, nas universidades ou nos centros de formação para discutir e encontrar, em grupo ou individualmente, os caminhos para transformação de sua prática docente e a consequente aprendizagem das crianças. $O$ aperfeiçoamento do professor, a passagem de uma abordagem conservadora para uma abordagem inovadora requer que se provoque o professor a produzir, questionar, refletir, construir, criar ou projetar para produzir o conhecimento (BEHRENS, 2007), que significa, momentos de troca e de discussão, capacitação em serviço, para enfrentar os desafios que poderão surgir no cotidiano da atividade docente. 


\subsection{A pedagogia crítica e seus teóricos}

O paradigma inovador e/ou o paradigma emergente, citado por Alarcão (200I) e Behrens (2007), na perspectiva da pedagogia crítica, estimula o aluno e o professor, a se posicionaram sobre as crenças propostas, à problematizar conceitos, a construir a sua consciência crítica, encontra em autores tais como: Freire (2013) que trata da pedagogia problematizadora; de Adorno (1995) referindo-se às questões de emancipação; Mclaren (1997) tratar da posição do professor como educador crítico; Nóvoa (I995) retrata que os paradigmas de formação contribuem para o surgimento de professores reflexivos, protagonistas da transformação da escola; Giroux(1997) considera o professor como intelectual transformador, com o objetivo comum de fortalecer aqueles sem poder de modo a transformar desigualdades e injustiças sociais existentes.

Freire (2013) em seu livro Pedagogia do Oprimido o professor encontra-se na condição de oprimido, sendo que até somos considerados, pois não vemos professores serem convocados para pensar e produzir projetos ou programas para serem desenvolvidos nas escolas, não há estímulo para um pensar autêntico, vivificador, criador. Este autor reivindicava a educação como prática libertadora, sendo a formação do professor considerada como processo de busca de sua libertação, "a libertação autêntica, que é humanização em processo. [...] É práxis, que implica a ação e a reflexão dos homens sobre o mundo para transformá-lo" (FREIRE, 2013, p. 93). Uma formação comprometida com a libertação, com professores conscientes da problematização do homem e das relações que estabelece com o mundo, visando à emancipação. $O$ autor se reporta à necessidade de ação dialógica superando a pedagogia bancária da relação educador-educando, para a nova expressão educador-educando ou educando-educador, numa relação horizontal onde ambos, e juntos sobretudo, se tornando sujeitos do processo educativo.

Assim, entender essa movimentação, reporta-nos ao educador problematizador, no seu quefazer docente, que re-faz constantemente seu ato cognoscente, e em diálogo com os educandos atuem como investigadores críticos. Ao assumir sua posição de investigador crítico, professor e aluno buscam no diálogo criativo, reflexivo, desvelar a realidade para a emancipação de ambos. A concepção problematizadora, segundo Freire (2013), 
comprometese com a libertação, a emancipação e se empenha em desmitificar a realidade opressora, razão por que Freire afirma, acerca da concepção problematizadora que:

Tem no diálogo, o selo do ato cognoscente, desvelador da realidade. [...] Esta concepção, na medida em que, servindo a libertação, se funda na criatividade e estimula a reflexão e a ação verdadeiras dos homens sobre a realidade, responde à sua vocação, como seres que podem autenticar-se fora da busca e da transformação (2013, p. IOI).

Percebemos neste sentido que na concepção problematizadora há a presença efetiva do educador e do educando que assumem o centro do processo e buscam juntos a emancipação, a liberdade, contra o autoritarismo, a partir de uma postura democrática na sala de aula. Na perspectiva de Freire encontramos Mclaren (1997), que observa os professores como pesquisadores em educação, educadores críticos, que consideram o conhecimento como construção social, uma especificidade cultural dependente do contexto, do costume, da cultura e conduz à emancipação. Significa a presença de uma profunda articulação de sua pedagogia crítica com a pedagogia libertadora de Freire, pois têm preocupações comuns com os deserdados, excluídos, oprimidos. Os educadores, segundo Mclaren opõem-se à desregulamentação e abertura do sucesso escolar à lógica de mercado, que apenas perpetua o poder da classe hegemônica.

Esta perspectiva espera por meio da ação reflexiva, coletiva, crítica, criar condições sob as quais a irracionalidade, a dominação e a opressão sejam superadas e transformadas efetivamente. Mclaren (1997) aponta o desafio para os professores na sua formação continuada, no sentido de reconhecer e transformar as características antidemocráticas e opressivas do controle hegemônico, a fim de ressignificar a prática docente, de forma que o processo ensino e aprendizagem transforme-se num processo de investigação, de crítica, de construção de uma realidade mais justa, mais humana, e igualitária, numa linguagem de esperança.

A concepção de educação e de formação, para Adorno (1995) relaciona-se à conscientização, à produção de uma consciência plena, verdadeira, que alcança a emancipação. No entanto, o problema da emancipação, é internacional, pois somente existe democracia efetiva, que opera em conformidade com suas concepções numa sociedade de quem é emancipado. No entanto, este autor afirma que o objetivo da escola, e dos educadores é desbarbarizar a humanidade, sendo o pressuposto imediato da sobrevivência. Esta é uma 
tarefa ou desafio, dos mais difíceis de serem atingidos, pois a sociedade procura manter o homem não emancipado e para tanto, qualquer tentativa que conduza a sociedade à emancipação é submetida a resistências enormes. A sociedade atual é heterônoma, as pessoas aceitam aquilo que a exigência dominante apresenta à sua vista e lhe inculca à força sua ideologia. Nesta sociedade, Adorno (1995) diz que nenhuma pessoa pode existir ou agir conforme suas próprias determinações, de forma emancipada, enquanto isto as pessoas são formadas, quase que de forma inconsciente pelos inúmeros canais e instâncias mediadoras como, canais de TV, reportagens, novelas, propagandas, slogans, músicas, de um modo tal que tudo absorvem e aceitam nos termos da configuração heterônoma que se desvia de sua própria consciência.

Nóvoa (1995) chamam a atenção para as manobras políticas neoliberais quanto à necessidade de atividades relacionadas à formação continuada de professores no sentido de que a política tem impedido que os professores possam expressar seus pontos de vista ou não buscar o poder e permanecer proletários. Para este autor, são quatro os fatores que provocam o proletariado da profissão docente, ou seja, a separação entre a concepção e a implementação de programas e cursos na sua implementação educacional; padronização de tarefas; reduzir os custos necessários para a aquisição de mão de obra e; aumento da demanda por atividades na escola e em sala de aula. Esses fatores indicam o valor das características técnicas do trabalho dos professores, afastando-os do processo de sua autonomia profissional.

O autor diz ser necessário romper com estas "exigências impostas" e buscar um processo de investimento pessoal, livre e criativo de sua formação, com vistas à construção de sua identidade pessoal e profissional, procurando espaços de interação entre as dimensões pessoais e profissionais e permitindo aos professores apropriarem-se nos seus processos de formação e autoformação.

Nóvoa (2010) cita seis princípios importantes em qualquer formação de professores como: importância de refletir sobre o modo como a pessoa se forma (compreensão retrospectiva); processo de transformação individual que considera as dimensões do saber, saber-fazer e do saber-ser; articulação com as instituições onde os professores exercem sua atividade profissional; produção coletiva do saber; cariz estratégico para mobilização dos recursos teóricos e técnicos adquiridos durante a formação; e capacidade de superação de situações, pelo que consegue superar ou ultrapassar concepções retrógradas. 
Giroux (1997) considera os professores como intelectuais transformadores, no sentido de que pensam a educação a partir dos problemas reais, concretos, enfrentados pelos professores e estudantes. É possível verificar a proliferação de pacotes curriculares à prova de professor (GIROUX, 1997) sendo que essa fundamentação destina aos professores a implementação de conteúdos e instruções predeterminados, desvalorizando e desabilitando à prática docente crítica e construtiva. Desta modo reduz-se os professores ao status de técnicos especializados na burocracia escolar com a função de efetivar projetos e programas curriculares desvinculados da realidade circundante.

A partir das posições expressas por teóricos críticos sobre professores que os veem como intelectuais transformadores (GIROUX, 1997), que devem se apropriar do seu processo de formação e autoformação (NÓVOA, 1995), que devem romper com a educação enquanto mera apropriação de técnicas (ADORNO, 1995), que devem reconhecer e romper com a opressão e dominação (MCLAREN, 1995) e que devem atuar como educadores críticos (FREIRE, 1996).

Freire (2013), Mclaren (1997), Adorno (2011), Nóvoa (1995, 2010) e Giroux (1997) partilham a ideia de que homens e mulheres são intelectuais, e atuam na complexa tarefa de, interpretar e dar significado ao seu mundo, de participar de uma concepção de mundo particular (GIROUX, 1997), na qual teoria não dita a prática e sim, serve para manter a prática ao nosso alcance, de forma a mediar e compreender de maneira crítica o tipo de práxis necessária em um ambiente específico em um momento particular. Ainda de acordo com esses mesmos autores, a partir de uma prática docente responsável, reflexiva, crítica, transformadora e emancipadora, propõem uma postura firme, radical, em favor da vida humana e planetária.

Esta proposta, vem ao encontro do que propõe a LDB 9.394/96, ao apontar, no Título VI - Dos Profissionais da Educação, como fundamentos da formação dos profissionais da educação, a associação entre teorias e práticas com a capacitação em serviço (BRASIL, 1996). Portanto, reafirmamos que os educadores da educação infantil devem compreender a criança como um ser único e social, dotado de potencialidades e habilidades, mas os professores devem ajudar a desenvolver, como sugere RCNEI: "compreender, conhecer e reconhecer o jeito particular das crianças serem e estarem no mundo" (BRASIL, I998, p. 22) Para isso, é preciso criar vínculos entre professores e alunos, entre professores e famílias, 
pois o professor deve ser versátil, capaz de trabalhar com conteúdos de natureza diversas, para ser aprendiz ao longo de sua vida, refletir sobre as suas práticas e outras teorias Os professores devem compreender que as crianças são cidadãos, sujeitos históricos e sociais e que têm direitos aos quais o Estado deve obedecer.

[...] só é possível concretizar um trabalho com a infância, voltado para a construção da cidadania e a emancipação se os adultos envolvidos forem dessa forma considerados. Isso implica no entendimento de que os mecanismos de formação sejam percebidos como prática social inevitavelmente coerente com a prática que se pretende implantar na sala de aula e implica em salários, planos de carreira e condições de trabalho dignas (KRAMER, 1994, p. 19).

Entendemos, portanto, que ainda hoje, as políticas de formação ainda estão desvinculadas de um óbvio desenvolvimento de carreira, o que os professores não conseguem, com a formação recebida das secretarias municipais. O que existe é a diversidade de caminhos, conhecimentos, teorias e práticas, e os professores precisam expandir seus conhecimentos e desenvolver uma paixão pelo conhecimento.

Essa multiplicidade ou pluralidade significa "por em evidência que os processos de formação são espaços de construção de linguagem, de produção de muitas vozes, de conquista da palavra. Formação que como a voz, a palavra e a escrita é direito de todos" (KRAMER, 1994, p. 28).

Para que haja um aperfeiçoamento verdadeiro, é necessário sensibilizar os professores para a importância da sua formação continuada, reconstruir a sua prática docente sob os mais diversos aspectos, nas mais diversas situações de aprendizagem, para verdadeiramente o que é a formação continuada.

\section{${ }_{3}$ CONCLUSÃO}

O presente artigo apresentou distintas ideias sobre a formação continuada, a pedagogia crítica e os modelos dos autores referenciados, reafirmando que a educação continuada é extremamente necessária para o aperfeiçoamento do profissionalismo docente, pois a partir desta formação, os docentes são constantemente atualizados para encontrar soluções para os problemas que surgem no dia a dia, a fim de atingir os objetivos de aprendizagem e desenvolvimento das crianças. Significa assumir um papel responsável, 
crítico e construtivo no desenvolvimento de objetivos que, através da sua ação, procuram contribuir para a formação de cidadãos conscientes.

Em suma, reconhecemos a importância de ter uma compreensão clara dos padrões subjacentes à nossa formação e de assumir posturas autênticas, no sentido de qualificar continuamente e contribuir para a formação dos nossos colegas e, sobretudo, para a formação dos nossos alunos. Devemos, portanto, reconhecer que os objetivos da pedagogia crítica e de seus defensores são nos tornar produtores de saberes reforçadores no exercício da autonomia.

\section{REFERÊNCIAS}

ALARCÃO, Isabel. (org.) Escola reflexiva e nova racionalidade. Porto Alegre: Artmed, 2001.

ADORNO, Theodor W. Educação e Emancipação. Rio de Janeiro: Paz e Terra, 1995.

BEHRENS, Marilda A. O paradigma da complexidade na formação e no desenvolvimento profissional de professores universitários. Revista Educação. Porto Alegre/RS, ano XXX, n.3(63), p. 439-455, set./dez. 2007. Disponível em www.revistaseletronicas.pucrs. Acesso em I4/ II $/ 2021$.

BRASIL. Ministério da Educação e do Desporto. Referencial curricular nacional para a educação infantil (Rcnei). Ministério da educação e do Desporto. Secretaria de Educação Fundamental. Brasília - MEC/SEF, 1998.

BRASIL. Ministério da Educação. Lei de Diretrizes e Bases da Educação Nacional (LDB) no 9.394/96. Brasília: MEC, SEB, 1996.

FREIRE, Paulo. Pedagogia da autonomia: saberes necessários à prática educativa. $37^{\mathrm{a}}$ ed. São Paulo: Paz e Terra, 1996.

Pedagogia do oprimido. 54ª ed. Rio de Janeiro: Paz e Terra, 2013.

GIROUX, Henry A. Os professores como intelectuais: rumo a uma teoria crítica da aprendizagem. Porto Alegre: Artes Médicas, 1997. 
KRAMER, Sonia. Currículo de educação infantil e a formação dos profissionais de creche e pré-escola: questões teóricas e polêmicas. In: Por uma política de formação do profissional de educação infantil. MEC/ SEF/ COEDI- Brasília: MEC/SEF/COEDI, 1994.

MCLAREN, Peter. A vida nas escolas: uma introdução à pedagogia crítica nos fundamentos da educação. 2aㅡ ed. Porto Alegre: Artes Médicas, 1997.

NÓVOA, Antonio. Formação de professores e profissionais docentes. In: NÓVOA, Antonio. Os professores e sua formação. 2. Ed. Dom Quixote: Lisboa, Portugal, 1995.

. A formação tem que passar por aqui: as histórias de vida no Projeto PROSALUS. In: NÓVOA, Antonio; FINGER, Mathias. O método (auto)biográfico e a formação. Natal, RN: EDUFRN. São Paulo: Paulus, 2010.

PIMENTA, Selma G.; ANASTASIOU, Léa G.C.; CAVALLET, Valdo J. Docência no ensino superior: construindo caminhos. In: BARBOSA, Raquel L.L. (org.) Formação de educadores: desafios e perspectivas. São Paulo: Editora UNESP, 2003. 